\title{
HUBUNGAN KEPUASAN TERAPI DENGAN KUALITAS HIDUP PASIEN DIABETES MELLITUS TIPE-2 DI PELAYANAN PRIMER (PUSKESMAS JETIS 1 BANTUL)
}

\author{
Akrom, Muhammad Muhlis, Yenny Sri Wahyuni* \\ Universitas Ahmad Dahlan, Jl. Kapas No.9, Semaki, Kec. Umbulharjo, Kota Yogyakarta, \\ Daerah Istimewa Yogyakarta 55166, Indonesia \\ *yennysriwahyuni.1185@gmail.com \\ muhlis3@yahoo.co.id \\ akrom@pharm.uad.ac.id
}

\begin{abstract}
ABSTRAK
Diabetes adalah penyakit kronis serius yang terjadi karena pankreas tidak menghasilkan cukup insulin (hormon yang mengatur gula darah atau glukosa), atau ketika tubuh tidak dapat secara efektif menggunakan insulin yang dihasilkannya. Melitus merupakan sindrom metabolis kronis yang menjadi salah satu penyebab kematian terbesar di dunia. Desain Penelitian ini adalah penelitian jenis Observasional, dengan menggunakan pendekatan cross sectional, dimana subyek penelitian hanya diobservasi. Penelitian ini mengambil subyek sebanyak 109 pasien. Pengambilan data secara prosepektif dan dilakukan dengan cara mengumpulkan informasi dari pasien melalui wawancara tatap muka (face-to-face interview) menggunakan kuesioner. Kuesioner yang digunakan pada penelitian ini berjumlah dua kuesioner yaitu, data demografi pasien, kuesioner kepuasan (TSQM), kuesioner Kualitas Hidup (EQ5D).

Analisis data menggunakan Uji Statistik dengan bantuan SPSS versi 23. Data sosiodemografi pasien meliputi jenis kelamin, usia, pernikahan, pekerjaan, pendidikan dan penyakit penyerta pasien pendeita DM type 2 disajiakan dalam tabel distribusi frekuensi. Uji Chi Squaredilakukan untuk mengetahui hubungan antara sosio-demografi dengan kepuasan terapi dan hubungan sosio-demografi dengan kualitas hidup.

Hasil hitung dengan bantuan SPSS versi 23 menunjukkan bahwa nilai $p$ value $>0,05$ sehingga dapat disimpulkan bahwa tidak ada hubungan antara sosio-demografi dengan kepuasan terapi dan tidak ada hubungan antara sosio-demografi dengan kualitas hidup. Hubungan antara kepuasan terapi dengan kualitas hidup dilakukan uji korelasi Spearman's rho. Hasilnya diperoleh nilai $\mathrm{p}$ value $(0,006)<0,05$. dengan demikian dapat disimpukan bahwa terdapat hubungan antara kepuasan terapi dengan kualitas hidup pasien penderita DM type-2.
\end{abstract}

Kata Kunci: Diabetes melitus tipe 2, Kepuasan Terapi dan Kualitas Hidup

\begin{abstract}
Diabetes is a serious chronic disease that occurs because the pancreas does not produce enough insulin (a hormone that regulates blood sugar or glucose), or when the body cannot effectively use the insulin it produces (WHO, 2016). Melitus is a chronic metabolic syndrome that is one of the biggest cause of death in the world (ADA, 2017). The design of this study was an Observational type of research, using a cross sectional approach, where the research subjects were only observed. This study took 109 subjects. Data is collected in a perspective and carried out by collecting information from patients through face-to-face interviews using questionnaires. The questionnaire used in this study
\end{abstract}


amounted to two questionnaires namely, patient demographic data, satisfaction questionnaire (TSQM), Quality of Life questionnaire (EQ5D).

Data analysis used Statistical Tests with the help of SPSS version 23. The sociodemographic data of patients included gender, age, marriage, occupation, education and accompanying diseases of patients with type 2 DM presented in the frequency distribution table. Chi Squared Test was conducted to determine the relationship between sociodemographic with therapeutic satisfaction and socio-demographic relationship with quality of life.

The results of calculations with the help of SPSS version 23 show that the p value> 0.05 so that it can be concluded that there is no relationship between socio-demographic therapy and satisfaction with no relationship between socio-demographic with quality of life. The relationship between therapeutic satisfaction and quality of life was done by the Spearman's rho correlation test. The results obtained $p$ value $(0.006)<0.05$. thus it can be concluded that there is a relationship between the satisfaction of therapy with the quality of life of patients Diabetes Mellitus with type 2.

Keywords : Diabetes Mellitus type 2, Therapy Satisfaction and Quality of Life 


\section{PENDAHULUAN}

Diabetes adalah penyakit kronis serius yang terjadi karena pankreas tidak menghasilkan cukup insulin (hormon yang mengatur gula darah atau glukosa), atau ketika tubuh tidak dapat secara efektif menggunakan insulin yang dihasilkannya (WHO, 2016). Diabetes Melitus merupakan sindrom metabolis kronis yang menjadi salah satu penyebab kematian terbesar di dunia. Diabetes mellitus (DM) adalah faktor resiko utama dari penyakit kardiovaskular, gagal jantung, stroke dan gagal ginjal. Menurut American Diabetic Association (ADA) diabetes dibagi menjadi empat kelas yaitu, diabetes mellitus tipe 1, diabetes mellitus tipe 2, gestasional diabetes mellitus (diabetes karena kehamilan), dan diabetes tipe lain. Diabetes melitus merupakan penyakit kronis oleh karena itu membutuhkan pengobatan jangka panjang (ADA, 2017).

Jumlah penderita Diabetes Mellitus di dunia dari tahun ke tahun mengalami peningkatan. World Health Organization/WHO (2016), memperkirakan sebanyak 422 juta orang dewasa hidup dengan Diabetes Mellitus. Pada tahun 2035 jumlah tersebut diperkirakan akan naik menjadi 592 juta orang. Sedangkan IDF Atlas (2015),memaparkan bahwa 415 juta orang dewasa menderita DM dan diperkirakan pada tahun 2040 penderita DM akan naik menjadi 642 juta orang. Prevalensi penyakit diabetes mellitus yang tertinggi di indonesia pada tahun 2013 adalah Daerah Istimewa Yogyakarta yaitu sebesar 2,6\% (Kemenkes RI, 2014). Menurut data dari hasil Riset Kesehatan Dasar (Riskesdas) menunjukan prevalensi diabetes mellitus menurut kosensus PERKENI 2015 pada penduduk umur $\geq 15$ tahun adalah $10,9 \%$. Dari prevalensi yang tinggi tersebut menjadikan perlunya perhatian yang khusus pada penyakit diabetes mellitus baik dari kepatuhan minum obat, segi pengetahuan dan kepuasan yang didapatkan oleh pasien.

Kepuasan menurut Kamus Bahasa Indonesia adalah puas; merasa bahagia; merasa senang; perihal (hal yang bersifat puas, kebahagiaan, kesenangan, kelegaan dan sebagainya). Menurut Kotler (dalam Damping 2012) bahwa kepuasan adalah tingkat kepuasan seseorang setelah membandingkan kinerja atau hasil yang dirasakan dibandingkan dengan harapannya. Kepuasan pasien merupakan evaluasi atau penilaian setelah memakai suatu pelayanan, bahwa pelayanan yang dipilih setidak-tidaknya memenuhi atau melebihi harapan (Mamik, 2010). Jadi kepuasan atau ketidakpuasan adalah kesimpulan dari suatu interaksi antara harapan dan pengalaman seseorang sesudah memakai jasa atau pelayanan yang diberikan.

Kualitas hidup adalah persepsi individual terhadap posisinya dalam kehidupan, yang ditinjau dalam konteks budaya, sistem nilai individu dimana mereka berada dan hubungannya terhadap tujuan hidup, harapan, kesenangan, dan perhatian dan lainnya yang terkait. Masalah yang mencakup kualitas hidup sangat luas dan kompleks termasuk masalah kesehatan fisik, status psikologik, tingkat kebebasan, hubungan sosial dan lingkungan dimana mereka berada (World Health Organization, 2012).

Profil kesehatan kabupaten Bantul menyebutkan bahwa diabetes mellitus termasuk kedalam 10 besar penyakit di puskesmas dengan angka kunjungan yang terus menerus mengalami peningkatan dibandingkan tahun - tahun sebelumnya (Dinkes bantul, 2018). Pada puskesmas jetis 1 bantul, kunjungan pasien diabetes mellitus memperlihatkan angka yang cukup tinggi (Anonim, 2017). 
Penelitian ini dilakukan dengan harapan mendapatkan gambaran mengenai hubungan kepuasan terapi dengan kualitas hidup pasien diabetes mellitus tipe 2 dipelayanan primer (Puskesmas Jetis 1 Bantul).

\section{METODE PENELITIAN}

\section{Jenis, tempat dan waktu penelitian}

Penelitian cross sectional ini dilakukan di Pelayanan Kesehatan Primer Jetis 1 Bantul Yogyakarta Indonesia selama 2 minggu yakni dari 14 oktober sampai 01 November 2019

\section{Instrumen Penelitian}

Pengambilan data menggunakan kuesioner dan rekam medis (sosio demografi). Pengukuran kepuasan dan kualitas hidup yang telah diuji validasi dan reliabelitas pada pasien diabetes di Indonesia. Penggunaan kuesioner lebih mudah diintegrasikan ke dalam praktek klinis. Kuesioner TSQM dan EQ5D bergantung pada subjek dalam melaporkan kepuasan dan kualitas hidup. Kuesioner TSQM terdiri dari 14 pertanyaan dengan skala frekuensi 1 sampai 7 (amat sangat tidak puas, sangat tidak puas, tidak puas, cukup puas, puas, sangat puas, amat sangat puas). EQ-5D VAS mencatat penilaian responden terhadap kesehatannya menggunakan visual analogue scale berbentuk vertikal. Penilaian kualitas hidup EQ5D-3L dapat dilakukan dengan 3 cara, yaitu secara deskriptif dengan melihat proporsi pasien berdasarkan level kualitashidup (level 1-3), menggunakan nilai index dan nilai VAS. Nilai index dan VAS disajikan dalam bentuk nilai rerata $(\mathrm{X} \pm \mathrm{SD})$. Nilai index dalam penelitian ini mengacu pada set valuedari Indonesia yang telah dilakukan dalam penelitian Purbaet al. (2017). Nilai set value memiliki range -0,865-1,000, dimananilai yang mendekati 1,000 menunjukkankualitas yang semakinbaik, sedangkannilai EQVAS memiliki range skor 0-100, dimanaskor VAS yang mendekati 100 menggambarkankualitashidup yang semakinbaik (Purba et al., 2017; Reenen et al., 2018).

\section{Ijin Penelitian}

Penelitian ini telah dikaji dan diperoleh izin dari komite etik Universitas Ahmad Dahlan Yogayakarta Indonesia (Ethical Clearance Ref: 011909098) tahun 2019.

\section{Kriteria Inklusi dan Eksklusi}

Rekrutmen responden secara random dan memenuhi kriteria inklusi. Kriteria inklusi yakni pasien rawat jalan berumur 18-85 tahun, diagnosa diabetes tipe 2 dengan atau tanpa komplikasi, menerima minimal satu obat antidiabetes selama 3 bulan terakhir, bersedia ikut penelitian. Wanita hamil dan mengalami gangguan pendengaran dan penglihatan akan dieksklusi dari penelitian ini. 


\section{Sampel Size Penelitian}

Perhitungan sampel size menggunakan kalkulator open epi (online) dengan deviat baku alfa $=1,96$ (Tingkat kepercayaan 95\%, deviat baku beta $=0,84$ (Power of test $80 \%$ ), Percent of controls exposed $=36$ (diambil dari data penelitian sebelumnya) Persent of case with exposure $=63$. Minimal sampel berdasarkan perhitungan sebanyak 109 orang pada populasi 120 orang.

\section{Analisis}

Data yang diperoleh dilakukan analisis Chi square dilanjutkan Uji normalitas yang digunakan untuk semua variabel adalah uji Kolmogorof Semirnov. Uji compare means digunakan untuk mengetahui perbedaan rata-rata kategori kepuasan dan kualitas hidup. Analisis menggunakan SPSS versi 23.

\section{Hasil dan Diskusi}

\section{Karakteristik Pasien}

Responden yang ikut dan memenuhi kriteria inklusi dalam penelitian ini yakni 109. Karakteristik pasien dalam Karakteristik sosio-demografi pasien diantaranya jenis kelamin, usia, pendidikan, pekerjaan, pernikahan, penghasilan, dan penyakit penyerta. Karakteristik pasien dalam penelitian ini bahwa berdasarkan jenis kelamin, mayoritas subyek penelitian adalah perempuan sebanyak 83 orang $(76,1 \%)$. Sedangkan subyek laki-laki berjumlah 26 orang $(23,9 \%)$. Usia pasien yang mendominasi adalah rentang 18-85 tahun, dengan rincian yang berusia $\leq 50$ tahun sebanyak17orang $(15,6 \%)$. Sedangkan yang berusia diatas 50 tahun sebanyak 92 orang $(84,4 \%)$. Status pernikahan pasien seluruhnya telah menikah 109 orang $(100 \%)$. Status pernikahan menandakan seseorang telah dewasa. Penghasilan pada subyek yang kurang dari Rp. 950.000,- yaitu 82 orang $(75,2 \%)$, sedangkan subyek yang lebih dari sama dengan Rp.950.000,- yaitu 27 orang (24,8\%). Berdasarkan karakteristik penyakit penyerta pada pasien, sebanyak 72 orang $(66,1 \%)$ terdapat penyakit penyerta. sedangkan 37 orang $(33,9 \%)$ tanpa penyakit penyerta. Karakteristik pasien dalam penelitian ini dapat dilihat pada Tabel 1.

Tabel 1. Karakteristik Pasien Diabetes

\begin{tabular}{lcc}
\multicolumn{1}{c}{ Karakteristik Pasien } & $\begin{array}{c}\text { Subyek } \\
\text { Jumlah (n=109) }\end{array}$ & $\%$ \\
\hline Jenis Kelamin & & \\
1. Laki-laki & 26 & 23,9 \\
2. Perempuan & 83 & 76,1 \\
Usia & & \\
$1 . \leq 50$ tahun & 17 & 15,6 \\
2. $>50$ tahun & 92 & 84,4 \\
Pendidikan & & \\
1. Dasar & 66 & 60,6 \\
2. Lanjutan & 43 & 39,4 \\
Pernikahan & & \\
1. Menikah & 109 & 100,0
\end{tabular}


2. Belum menikah

\section{Penghasilan}

1. $<906.000$,-

2. $\geq 906.000$,-

\section{Penyakit Penyerta}

1. Terdapat penyakit penyerta

2. Tidak terdapat penyakit penyerta
0

82

75,2

$27 \quad 24,8$

$72 \quad 66,1$

$37 \quad 33,9$

\section{Penilaian Terhadap Kepuasan Terapi}

Berdasarkan hasil dari penilaian kepuasan terapi dengan menggunakan kuesioner TSQM secara umum maupun berdasarkan domain kepuasan terapi pada jumlah subyek yaitu 109 sampel, diperoleh nilai rerata tingkat kepuasan untuk domain efektifitas yaitu $61,583 \pm 11,598(61,6 \%)$, untuk domain efek samping rerata tingkat kepuasannya yaitu 54,479 $\pm 32,197(54,5 \%)$, untuk rerata tingkat kepuasan domain kenyamanan yaitu $66,883 \pm 8,809(66,9 \%)$, dan untuk domain kepuasan global niai rerata tingkat kepuasan 55,712 $\pm 11,268(55,7 \%)$. Ragam kepuasan dalam peneltian ini berdasarkan TSQM dapat dilihat pada Tabel 2.

Berdasarkan hasil pengukuran tingat kepuasan terapi yang disajikan tabel 3 diatas dapat dijelaskan bahwa pasien yang merasa puas sebanyak 10 orang $(9,2 \%)$, yang merasa sangat puas 92 orang $(84,4 \%)$ dan yang amat sangat puas 7 orang $(6,4 \%)$. Jadi dapat disimpulkan bahwa mayoritas pasien merasa sangat puas terhadap pelayanan yang diterima oleh mereka.

Tabel 2. Penilaian Kepuasan Terapi Pasien Diabetes Mellitus tipe 2 di Puskesmas Jetis 1 Bantul Yogyakarta

\begin{tabular}{clccc}
\hline No & \multicolumn{1}{c}{ Domain } & Rerata & $\mathrm{n}$ & $\%$ \\
\hline 1 & Efektifitas & $61,583 \pm 11,598$ & 109 & 61,6 \\
2 & Efek samping & $54,479 \pm 32,197$ & 109 & 54,5 \\
3 & Kenyamanan & $66,883 \pm 8,809$ & 109 & 66,9 \\
4 & Kepuasan global & $55,712 \pm 11,268$ & 109 & 55,7 \\
\hline
\end{tabular}

Tabel 3. Tingkat Kepuasan Terapi Pasien Diabetes Mellitus tipe 2 di Puskesmas Jetis 1 Bantul Yogyakarta

\begin{tabular}{clcl}
\hline No & \multicolumn{1}{c}{ Kepuasan } & \multicolumn{1}{c}{$\mathrm{n}$} & \multicolumn{1}{c}{$\%$} \\
\hline 1 & Puas & 10 & 9,2 \\
\hline 2 & Sangat Puas & 92 & 84,4 \\
\hline 3 & Amat Sangat Puas & 7 & 6,4 \\
\hline \multicolumn{2}{c}{ Total } & 109 & 100,0 \\
\hline
\end{tabular}




\section{Penilaian Terhadap Kualitas Hidup}

Penilaian domain kualitas hidup dengan menggunakan kuesioner EQ5D berdasarkan kemampuan berjalan/bergerak didominasi oleh tidak ada masalah dalam hidup nya yaitu 103 (94,5\%), bermasalah sedang 6 (5,5\%). Berdasarkan perawatan diri di dominasi oleh tidak ada masalah dalam hidup nya yaitu 106 $(97,2 \%)$, bermasalah sedang $3(2,8 \%)$, berdasarkan kegiatan yang biasa dilakukan di dominasi oleh tidak ada masalah dalam hidup nya yaitu $102(93,6 \%)$, bermasalah sedang $7(6,4 \%)$, berdasarkan rasa kesakitan / tidak nyaman yaitu tidak ada masalah dalam hidup $37(33,9 \%)$, bermasalah sedang yaitu $66(60,6 \%)$, bermasalah berat 6 $(5,5 \%)$, rasa cemas/ depresi yaitu tidak bermasalah dalam hidup $65(59,6 \%)$, bermasalah sedang yaitu $41(37,6 \%)$, bermasalah berat yaitu $3(2,8 \%)$. Dari beberapa dimensi kualitas hidup pasien diabetes mellitus tipe 2 di puskesmas jetis 1 bantul yaitu tidak ada masalah dalam hidupnya, mereka masih bisa melakukan apapun sendiri dan tidak ada kesusahan sama sekali. Dan yang mengalami masalah berat rata-rata dari pasien yang sudah lansia. Dapat dilihat dalam tabel 4.

Tabel 4. Penilaian kualitas hidup pasien diabetes mellitus tipe 2 di puskesmas jetis 1 Bantul Yogyakarta

\begin{tabular}{|c|c|c|c|c|c|c|c|}
\hline \multirow[t]{2}{*}{ No } & \multirow[t]{2}{*}{ Domain } & \multicolumn{2}{|c|}{ TB } & \multicolumn{2}{|c|}{ BS } & \multicolumn{2}{|c|}{$\mathrm{BB}$} \\
\hline & & $\mathrm{n}$ & $\%$ & $\mathrm{n}$ & $\%$ & $\mathrm{n}$ & $\%$ \\
\hline 1 & Kemampuan berjalan/bergerak & 103 & 94,5 & 6 & 5,5 & 0 & 0 \\
\hline 2 & Perawatan diri & 106 & 97,2 & 3 & 2,8 & 0 & 0 \\
\hline 3 & Kegiatan yang biasa dilakukan & 102 & 93,6 & 7 & 6,4 & 0 & 0 \\
\hline 4 & Rasa kesakitan/tidak nyaman & 37 & 33,9 & 66 & 60,6 & 6 & 5,5 \\
\hline 5 & Rasa cemas/depresi & 65 & 59,6 & 41 & 37,6 & 3 & 2,8 \\
\hline
\end{tabular}

Tabel 5. Rerata kualitas hidup pasien diabetes mellitus tipe 2 di puskesmas jetis 1 Bantul Yogyakarta:

\begin{tabular}{clccc}
\hline No & \multicolumn{1}{c}{ Domain } & Rerata & $\mathrm{n}$ & $\%$ \\
\hline 1 & Kemampuan bergerak & $98,167 \pm 7,630$ & 109 & 98,2 \\
\hline 2 & Perawatan diri & $99,083 \pm 5,473$ & 109 & 99,1 \\
\hline 3 & Kegiatan yang biasa dilakukan & $97,861 \pm 8,201$ & 109 & 97,9 \\
\hline 4 & Rasa kesakitan/Tidak Nyaman & $76,779 \pm 18,415$ & 109 & 76,8 \\
\hline 5 & Rasa Cemas/Depresi & $85,640 \pm 18,337$ & & 85,6 \\
\hline
\end{tabular}

Kualitas hidup domain kemampuan bergerak diperoleh nilai rerata 98,167 $\pm 7,630$ $(98,2 \%)$. Pada domain perawatan diri diperoleh nilai rerata 99,083 $\pm 5,473(99,1 \%)$. Pada domain kegiatan yang biasa dilakukan diperoleh nilai rerata 97,861 $\pm 8,201$ (97,9\%). Pada domain rasa kesakitan diperoleh nilai rerata 76,779 $\pm 18,415(76,8 \%)$ dan pada domain rasa cemas/depresi diperoleh nilai rerata 85,640 $\pm 18,337(85,6 \%)$ 


\section{Hubungan Sosio demografi, Kepuasan dan Kualitas Hidup}

Telah dijelaskan pada sub bab sebelumnya tentang gambaran karakteristik sosio demografi pasien penderita DM type-2, kepuasan pelayanan dan kualitas hidup pasien. Tentu saja hal ini belum mengambarkan ada tidaknya hubungan antara sosio demografi pasien dengan tingkat kepuasan dan kualitas hidup. Untuk mendapatkan data tersebut perlu dilakukan uji statistik. Uji statistik yang akan digunakan tegantung keadaan data penelitian. oleh karena itu sebelum dilakukan uji statistik terlebih dahulu dilakukan uji normalitas. Uji normalitas yang saya gunakan adalah Uji normalitas Kolmogorov Smirnov.

Tabel 6. Hasil Uji Normalitas dengan Komogorov Smirnov

\begin{tabular}{clcl}
\hline No & \multicolumn{1}{c}{ Variabel } & P value & Keterangan \\
\hline 1 & Jenis kelamin & 0,000 & distribusi data tidak normal \\
\hline 2 & Usia & 0,000 & distribusi data tidak normal \\
\hline 3 & Pendidikan & 0,000 & distribusi data tidak normal \\
\hline 4 & Pekerjaan & 0,000 & distribusi data tidak normal \\
\hline 5 & Penyakit Penyerta & 0,000 & distribusi data tidak normal \\
\hline 6 & Kepuasan & 0,200 & distribusi data normal \\
\hline 7 & Kualitas hidup & 0,000 & distribusi data tidak normal \\
\hline
\end{tabular}

Tabel 7. Hasil Chi Square antara Sosio demografi dengan Kepuasan Terapi dan Kulaitas Hidup

\begin{tabular}{clcc}
\hline No & \multicolumn{1}{c}{ Variabel } & P value & Keterangan \\
\hline 1 & Jenis kelamin VS Kepuasan & 0,149 & tidak ada hubungan \\
\hline 2 & Usia VS Kepuasan & 0,920 & tidak ada hubungan \\
\hline 3 & Pendidikan VS Kepuasan & 0,653 & tidak ada hubungan \\
\hline 4 & Pekerjaan VS Kepuasan & 0,940 & tidak ada hubungan \\
\hline 5 & Penyakit Penyerta VS Kepuasan & 0,441 & tidak ada hubungan \\
\hline 6 & Penghasilan VS Kepuasan & 0,429 & tidak ada hubungan \\
\hline 7 & Jenis kelamin VS Kualitas hidup & 0,184 & tidak ada hubungan \\
\hline 8 & Usia VS Kualitas hidup & 0,687 & tidak ada hubungan \\
\hline 9 & Pendidikan VS Kualitas hidup & 0,560 & tidak ada hubungan \\
\hline 10 & Pekerjaan VS Kualitas hidup & 0,213 & tidak ada hubungan \\
\hline 11 & Penyakit Penyerta VS Kualitas hidup & 0,536 & tidak ada hubungan \\
\hline 12 & Penghasilan VS Kualitas hidup & 0,179 & tidak ada hubungan \\
\hline & & & \\
\hline
\end{tabular}

Berdasarkan hasil uji chi square diperoleh hasil bahwa antara sosio demografi yaitu jenis kelamin, usia, pendidikan, pekerjaan, penyakit penyerta dan pengasilan tidak ada hubungan dengan kepuasan terapi pasien. Hal ini berdasarkan hasil hitung chi square dengan $P$ value $>0,05$. 


\section{Hubungan Kepuasan Terapi dengan Kualitas Hidup}

Untuk mengetahui ada tidaknya hubungan antara kepuasan terapi dengan kualitas hidup pasien digunakan Uji statistik nonparametrik yaitu Uji Korelasi Spearman's Test. Dengan bantuan SPSS versi 23 diperoleh hasil sebagai berikut :

Tabel 8. Hasil Uji Korelasi Spearman's Test antara Kepuasan Terapi dengan Kualitas Hidup

\begin{tabular}{cccc}
\hline $\mathrm{N}$ & & & \\
$\mathrm{O}$ & Variabel & $\mathrm{P}$ value & Keterangan \\
\hline 1 & Kepuasan VS Kualitas hidup & 0,006 & ada hubungan \\
\hline
\end{tabular}

Berdasarkan hasil uji statistik dengan Uji korelasi Spearman's Test diperoleh hasil $P$ value sebesar 0,006 . Berdasarkan kaidah kepurusan hipotesis sebagai berikut :

1) Jika $\mathrm{P}$ value $>0,05$ maka Ho diterima dan Ha ditolak

2) Jika $P$ value $<0,05$, maka Ho ditolak dan Ha diterima

Berdasarkan hasil menunjukkan bahwa $P$ value $(0,006)<0,05$, maka Ha diterima. Artiya terdapat hubungan yang signifikan antara kepuasan terapi dengan kualitas hidup.

Penelitian ini memiliki keterbatasan diantaranya kemungkinan terdapat bias recall dalam penelitian ini karena desain penelitian cross sectional. Mahasiswa yang terlibat dalam penelitian ini sudah menjalani pelatihan hal ini untuk memperkecil adanya variasi selama pengambilan data. Penelitian ini merupakan bagian awal dari penelitian pengembangan model asuhan kefarmasian pasien diabetes mellitus di pelayanan primer.

\section{KESIMPULAN}

1. Pada karakteristik pasien, jenis kelamin wanita yang lebih mendominasi penyakit diabetes mellitus di puskesmas jetis 1 bantul yaitu $(76,1 \%)$ sedangkan laki-laki $(23,9 \%)$. Sedangkan usia yang mendominasi yaitu usia diatas 50 tahun $(84,4 \%)$, sedangkan dibawah 50 tahun $(15,6 \%)$. Pendidikan dasar $(60,6 \%)$, mendidikan lanjutan $(39,4 \%)$. Pada pernikahan rata-rata subyek sudah menikah yaitu (100\%). Penghasilan pasien rata-rata dibawah Rp.950.000,- (75,2\%), sedangkan diatas Rp.950.000,- $(24,8 \%)$. Pada penyakit penyerta, yang memiliki penyakit penyerta $(66,1 \%)$, sedangkat yang tidak memiliki penyakit penyerta $(33,9 \%)$.

2. Pada kepuasan terapi diperoleh persentase untuk dimensi efektifitas yaitu $61,6 \%$, untuk dimensi efek samping yaitu 54,5\%, untuk dimensi kenyamanan yaitu $66,9 \%$, untuk kepuasan global 55,7\%.

3. pada kualitas hidup pasien diperoleh kemampuan berjalan/bergerak didominasi oleh tidak ada masalah dalam hidup nya yaitu 103 (94,5\%), bermasalah sedang $6(5,5 \%)$. Berdasarkan perawatan diri di dominasi oleh tidak ada masalah dalam hidup nya yaitu $106(97,2 \%)$, bermasalah sedang $3(2,8 \%)$, berdasarkan kegiatan yang biasa dilakukan di dominasi oleh tidak ada masalah dalam hidup nya yaitu $102(93,6 \%)$, bermasalah sedang $7(6,4 \%)$, berdasarkan rasa 
kesakitan / tidak nyaman yaitu tidak ada masalah dalam hidup 37 (33,9\%), bermasalah sedang yaitu $66(60,6 \%)$, bermasalah berat $6(5,5 \%)$, rasa cemas/ depresi yaitu tidak bermasalah dalam hidup $65(59,6 \%)$, bermasalah sedang yaitu $41(37,6 \%)$, bermasalah berat yaitu $3(2,8 \%)$.

\section{UCAPAN TERIMAKASIH}

Terima kasih kepada DR. dr. Akrom, M.Kes dan Muhammad Muhlis, S.Si., Sp.FRS., Apt sebagai Pembimbing. Terima kasih kepada Laila Nurrohma, Putri Awalia Zuchroh Baeti Nur, Caesar Bagus Reyaldi sebagai teman satu timdalam penelitian ini dan pihak puskesmas Jetis 1 Bantul Yogyakarta yang telah membantu jalannya penelitian ini.

\section{DAFTAR PUSTAKA}

Adikusuma W., Perwitasari D.A. and Supadmi W., 2016, Pengukuran Kualitas Hidup Pasien diabetes Mellitus tipe 2 yang Mendapat Antidiabetik Oral di Rumah Sakit PKU Muhammadiyah Bantul, Yogyakarta, Jurnal Ibnu Sina, 1(1), 1-8.

Alfian R.,A.M.P 2017 Uji Validitas Dan Reabilitas Kueisoner Medication Adherence Report Scale (MARS) Terhadap Pasien Diabetes Melitus. JIIS, 2(2), 176-183

American Diabetes Association [ADA]. (2017). Diagnosis and Classification of Diabetes Mellitus. Diabetes Care. Jan; 34(Suppl 1): S62-S69, doi: 10.2337/dc11-S062 ,PMCID: PMC3006051.

American Diabetes Association (ADA). (2014). Diagnosis and Classification of Diabetes Mellitus. Diabetes Care.

American Diabetes Association (ADA) (2015). Diagnosis and classification of diabetes mellitus. American Diabetes Care, Vol.38.

Anonim 2017. Profil Puskesmas Jetis 1 tahun 2017. Puskesmas Jetis 1 Bantul, Yogyakarta

Ardhany SD (2014), Pengaruh Brief Counseling dan Short Messages Service (SMS) terhadap Kepuasan Terapi dan Kualitas Hidup Pasien Diabetes Mellitus dengan Hipertensi Rawat Jalan di Poliklinik Penyakit dalam RSUD Panembahan Senopati Bantul, Yogyakarta.

Citra Pradana DL (2013), Hubungan Kepuasan Terapi Diabetes dengan Kualitas Hidup Pasien Usia Lanjut di RSUP DR Kariadi Semarang, UGM Yogyakarta.

Clinical Diabetes Association [CDA]. 2013. Clinical Practice Guidelines for the Prevention and Management of Diabetes in Canada.

Chronic disease and Quality of life in Western Australia, June 2007 (health outcomes assesment unit, epidemiology branch analysis and perfomance reporting).

Dipiro. JT., 2009, Pharmacoterapy Handbook 7th edition, Mc Graw Hill, New York. 
DiPiro J.T., Wells B.G., Schwinghammer T.L. and DiPiro C. V., 2015, Pharmacotherapy Handbook, Ninth Edit., McGraw-Hill Education Companies, Inggris.

Fatimah, R. N. (2015). Diabetes melitus tipe 2. J Majority, 4, 93-101.

Gultom, Y, T. (2012). Tingkat Pengetahuan Pasien Diabetes Melitus tentang Managemen Diabetes Melitus di Rumah Sakit Angkatan Darat Gatot Soebroto Jakarta Pusat. Karya Tulis Ilmiah Strata Satu. Depok: Fakultas Ilmu Keperawatan, Universitas Indonesia. Diakses pada 18 Agustus 2019.

Hasina, Raisya. (2014). Hubungan Tingkat Kepatuhan dan Kepuasan Terapi Dengan Kualitas Hidup Pasien Usia Lanjut Diabetes Mellitus Tipe II di Klinik Geriatri RSUP Dr. Sardjito Yogyakarta. .Diunduh 16 Agustus 2019 International Diabetes Federation. (2015). IDF Diabetes Atlas Seventh Edition 2015. Dunia : IDF

International Diabetes Federation (IDF). (2014). IDF Diabetes Atlas, diakses pada 19 Agustus 2019 dari http://www.idf.org/atlasmap/atlasmap

Khanazas, I. Pertiwi O.D. (2010). Analisis Pengaruh Kualitas Pelayanan Terhadap Kepuasan Konsumen RS St. Elisabeth Semarang. Vol.12, No.2, 2010.

Kusumadewi MD. 2011 Peran Stresor harian, Optimisme Dan Regulasi Diri Terhadap Kualitas Hidup Individu Dengan Diabetes Mellitus Tipe 2. Jurnal Psikologi Islam.

Kumar, G., Pavithra, A.M., 2014. Quality of Life (QOL) and Its Associated Factors Using WHOQOL-BREF Among Elderly in Urban Puducherry, India. Journal of Clinical and Diagnostic Research. 2014 Jan, Vol-8(1): 54- 57. Diakses dari http://www.ncbi.nlm.nih.gov/pubmed/24596723 (18 Agustus 2019).

Mamik. 2010. Organisasi \& Manajemen: Pelayanan Kesehatan dan Kebidanan. Jakarta. Prins Media.

Molloy et al.Type D personality, Self-efficacy and medicatio adherencefollowingan acute coronary syndrom. Psychosom Med 74 (1):100-106. 2012

Nimas, Ayu Fitriana. Tri, Kurniati Ambarani. (2012). Kualitas Hidup Pada Pasien Kanker Serviks yang Menjalani Pengobatan Radioterapi.Jurnal Psikologi Klinis dan Kesehatan Mental.Vol. 1. No. 02.

Notoatmodjo Soekidjo 2010, Promosi Kesehatan dan Ilmu Perilaku, Jakrta: Rineka Cipta

Notoatmodjo Soekidjo., 2014. Metodologi Penelitian Kesehatan. Rineka Cipta, Jakarta

Ozougwu, J. C.1, Obimba, K. C.2, Belonwu, C. D.3, and Unakalamba, C. B. The pathogenesis and pathophysiology of type 1 and type 2 diabetes mellitus. Journal of Physiology and Pathofisiology. 2013 Sep 4 (4): 46-57.

Pukeliene, V., \& Starkauskiene, V. (2011). Quality of Life: Factors Determining its Measurement Complexity. Journal Of Inzinerine EkonomikaEngineering Economics, 22 (2), 147-156.

PERKENI, 2015, Pengelolaan dan Pencegahan Diabetes Melitus Tipe 2 di Indonesia, PERKENI, Jakarta.

PERKENI. 2011. Konsensus pengelolaan diabetes melitus tipe 2 di indonesia 2011. Semarang: PB PERKENI. 
Powers F (2010). Does emotional stress cause type 2 diabetes? A review from the europeaan depression in diabetes (EDID) research Consortium. Discovery Medicine, 9(45) pp 112-8.

Purba, Fedrick Dermawan, et al. (2017). The Indonesian EQ-5D-5L Value Set. PharmacoEconomics. Volume 35(11): 1153-1165

Reenen, M. dan Janssen, B., 2015, EQ-5D-5L User guide: Basic Information on How to Use the EQ-5D-5L Instrument, EuroQol Group.

Reis, J. J. F., Gomes, M. K., Rodrigues, J., Gosling, A. P., Fontana, A. P., \& Cunha, A. J. L. A., (2013). Pain and its consequences in quality of life: a study with WHOQOL-Bref in leprosy patients with neuropathic pain. Hindawi Publishing Corporation, 1-7

Riset Kesehatan Dasar(Riskesdas). (2013). Badan Penelitian dan Pengembangan Kesehatan Kementerian RI tahun 2013.Diakses: 19 Agustus 2019.

Retnowati N, Satyabakti P. (2015) Hubungan Dukungan Keluarga dengan Kualitas Hidup Penderita Diabetes Mellitus di Puskesmas Tanah Kalikedinding. JurnalBerkala Epidemiologi.

Rizkifani, S., Perwitasari, D.A., Supadmi, W., 2014, Pengukuran Kualitas Hidup Pasien Diabetes Melitus di RS PKU Muhammadiyahtul Bantul, Fakultas Farmasi, Universitas Ahmad Dahlan, Yogyakarta

Sari, D. N. (2018). Hubungan antara self efficacy dengan self care pada penderita diabetes melitus tipe 2 di poliklinik penyakit dalam rsup m.djamil padang. Padang: Universitas Andalas. Skripsi.

Sarwono, Sarlito Wirawan. 2001. Psikologi Remaja. Jakarta: Raja Grafindo Persada.

Silitonga R., 2007. Faktor associate with Quality of Life on Parkinson Disease in Neurology Out Patient Department of Dr Kariadi Hospital. Ilmu Penyakit Saraf Universitas Diponegoro. Tesis

Subekti I., 2009. Buku Ajar Penyakit Dalam: Neuropati Diabetik, Jilid III, Edisi 4, Jakarta: FK UI pp. 1948.

Tang, S. T., Brown, B. Morton, Funnell, M. M., dan Aderson, M. R. (2007). ;Social Support, Quality of Life, and Self-Care Behaviors Among African Americans With Type 2 Diabetes $^{\text {ee }}$. The Diabetes Educator [online], Vol. 34, No. 2, March-April 2008, Hal. 266-276

Urifah, Rubbyana. (2012). Hubungan antara Strategi Koping dengan Kualitas Hidup Pada Pasien Skizofrenia Remisi Simptom.Jurnal Psikologi Klinis dan Kesehatan Mental.Vol. 1. No. 2

WHO. Global Report On Diabetes. France: World Health Organization; 2016.

Yusra Aini. (2011). Hubungan Dukungan Keluarga Dengan Kualitas Hidup Pasien Diabetes Mellitus Tipe II di Poliklinik Penyakit Dalam Rumah Sakit Umum Pusat Fatmawati Jakarta. Tesis Magister Ilmu Keperawatan Kekhususan Keperawatan Medikal bedah Fakultas Ilmu Keperawatan Universitas Indonesia. 